\title{
Feeding strategies and competition between terrestrial Haemadipsa leeches (Euhirudinea: Arhynchobdellida) in Danum Valley rainforest (Borneo, Sabah)
}

\author{
Piotr Gąsiorek and Hanna Różycka
}

Institute of Zoology and Biomedical Research, Jagiellonian University, Kraków, Poland

\begin{abstract}
Haemadipsid leeches are among the most successful terrestrial invertebrates in Bornean rainforests. They are very common ectoparasites of vertebrates, and their abundance has facilitated the conduction of numerous projects in the fields of ecology, zoogeography and taxonomy. We undertook research on two species inhabiting lowland dipterocarp forest, Haemadipsa picta Moore, 1929 and Haemadipsa subagilis (Moore, 1929), in order to address the following questions: (a) is there a difference in leech abundance between trails and off-trails?; (b) is ambush location dependent on specimen size or is species-specific?; (c) is intra- and interspecific competition limited by differences in foraging behaviours or vertical niche partitioning? Our results clearly show that $H$. picta is more abundant on trails than on off-trails and is vertically dispersed within the understory; the size of a specimen is strongly correlated with plant height. Haemadipsa subagilis was found not to exhibit such patterns. We suggest a possible lowering of interspecific competition between these species as a result of: (i) size-dependent dispersion of H. picta (together with reduction of intraspecific competition); and (ii) habitat specialisation of $H$. subagilis. Moreover, we provide new observations on their foraging behaviour.
\end{abstract}

Keywords: ectoparasites, foraging behaviour, Haemadipsidae, haematophagy, parasitism

Tropical rainforests of South-East Asia are the biodiversity hot-spot for terrestrial leeches of the family Haemadipsidae (Euhirudinea: Arhynchobdellida), which comprises over $80 \%$ of all land leech species and includes the most species-rich genus Haemadipsa Tennent, 1859 (see Borda and Siddall 2004, 2010, Sket and Trontelj 2008). The leech fauna of the Oriental region has received much attention since the fundamental works of Moore $(1929,1935,1938)$. The tiger leech H. picta Moore, 1929 and two brown coloured species, namely H. subagilis (Moore, 1929) and H. sumatrana (Horst, 1883), are typical and widely dispersed elements of the Bornean lowland rainforest fauna (Sawyer et al. 1982, Govedich et al. 2004).

Many ecological aspects of the life history of haemadipsid species remain unresolved, including establishing an average life span for each species and species habitat preferences. Fogden and Proctor (1985) conducted some important studies on the feeding habits of species of Haemadipsa, and until now this was the only paper containing detailed data on growth after feeding and the length of time they can endure without a blood meal. In contrast, feeding strategies of aquatic leeches are better understood (Davies and Kasserra 1989, Kutschera 2003, Chin Teh et al. 2012).

The second essential work by Kendall (2012), provided insights into changes in leech species proportion in response to environment modification and how various abiotic factors, including temperature and humidity, affect their abundance and frequencies. Statistical analyses performed by him confirmed previous assumptions that the brown leech species complex (former $H$. zeylanica sensu lato, see Borda and Siddall 2010) is more frequent in primary tropical rainforest, whereas more disturbed environments are dominated by conspicuously coloured H. picta.

Biotic factors, such as competition and feeding strategies of hematophagous leeches, have not been examined so far. Parasites can be an important factor influencing host mortality and, therefore, their abundance in an ecosystem (Anderson and May 1978). However, it is not possible to simply apply this theory to ectoparasites, such as leeches, which normally do not kill their hosts. Since an ecological balance between sympatric species should exist (Inger and Greenberg 1966), the co-existence of several common sanguivorous invertebrate species in rainforests raises questions about the relationship between inter- and intraspecific competition and niche partitioning.

Due to unresolved issues related to leech inter- and intraspecific ecological relationships and foraging behaviour, we conducted a study to address the following questions: (a) for as much as the inter-habitat distribution of species of Haemadipsa is already known (Kendall 2012),

Address for correspondence: P. Gąsiorek, Institute of Zoology and Biomedical Research, Jagiellonian University, Gronostajowa 9, 30-387 Kraków, Poland. Phone: +48 126646455; E-mail: piotr.lukas.gasiorek@gmail.com 

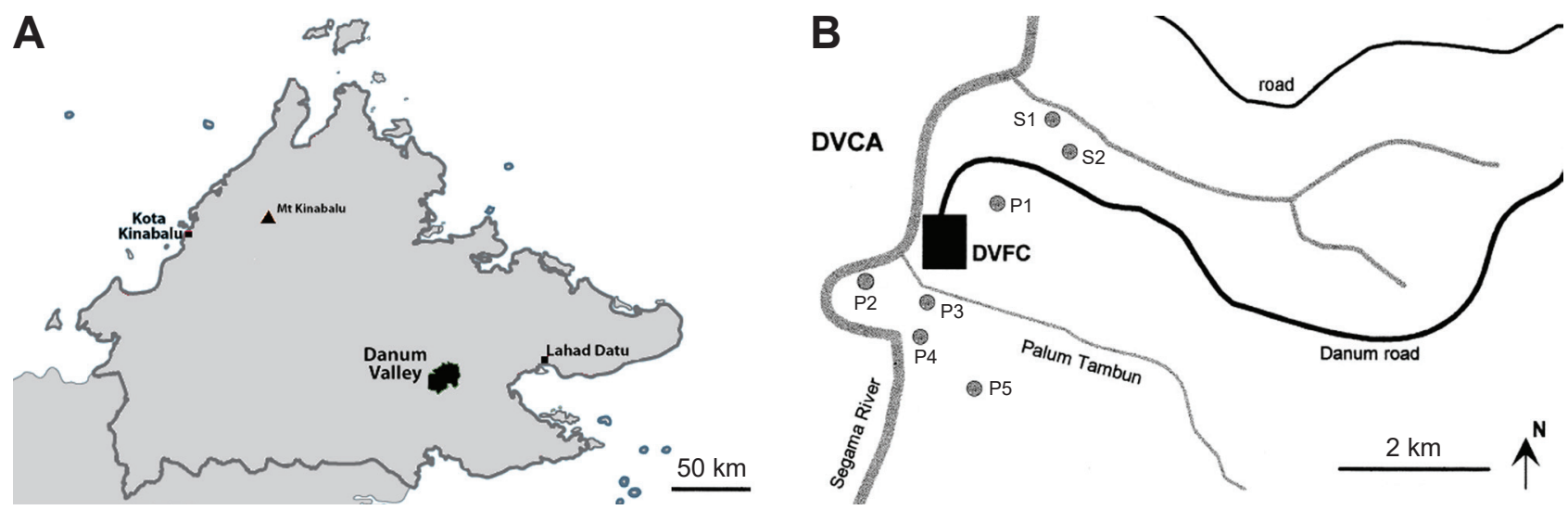

Fig. 1. A - Location of Danum Valley Conservation Area (DVCA) in Sabah (Malaysia); B - Danum Valley Field Centre (DVFC) vicinity. Grey circles signify sampling sites in the primary (P1-P5) and secondary (S1, S2) rainforest. Modified from Willott et al. (2000).

do $H$. picta and $H$. subagilis exhibit variable population densities as a result of greater host availability on trails $v s$ off-trails?; (b) as both species can be found on the ground, i.e. amongst leaf litter, as well as on the foliage of plants up to $2 \mathrm{~m}$ high (although preference of the brown leech species complex for the ground and $H$. picta for growing plants was noted - see Smythies 1959); when searching for a host, does the placement of the leech (forest litter $v s$ plant foliage) depend on body size or on species-specific preferences?; (c) do both species alter inter- and intraspecific competing changes in feeding strategies?

\section{MATERIALS AND METHODS}

The present study was carried out during a Tropical Ecology Field Course over three weeks in July 2016 in Danum Valley (Borneo, Sabah) (Fig. 1A). Two common Bornean haemadipsid species were chosen for analyses, Haemadipsa picta and H. subagilis. Taxa were identified on the basis of dorsum morphology, using the original description (Moore 1929) and the key by Govedich et al. (2004). Specimens were collected in seven sites identified after the reconnaissance, i.e. a preliminary two-daylong survey was conducted to determine localities characterised by average leech occurrence (where at least 10 leeches per halfhour were observed). Ultimately seven localities were chosen: five in the primary rainforest (P1-P5), and the other two in the secondary rainforest (S1, S2, approximately $100 \mathrm{~m}^{2}$ plots). Two localities in the primary rainforest and one in the secondary rainforest were in close proximity to rivers/ streams (localities P2, P3 and S1; see Fig. 1B). Primary rainforest in Danum Valley is dominated by trees from the family Dipterocarpaceae, with predominant Euphorbiaceae present in understory (Newbery et al. 1999). Secondary rainforest has a more dense understory, commonly composed of rattan palms (mainly of the genera Calamus, Daemonorops and Korthalsia; Johnson 1996); the canopy layer is uneven and with dominant Koompassia excelsa (Fabaceae). Individuals were collected twice per day (9-12 AM and 3-6 PM) from those areas closest to the trail (defined as an area extending no more than $1 \mathrm{~m}$ from a path) and off-trail (an area further than $1 \mathrm{~m}$ and no more than $15 \mathrm{~m}$ from a path) at each of the seven localities. One collecting session lasted approximately one and half hours. During the first three nights collecting sessions were
Table 1. Size classes of Haemadipsa picta Moore, 1929 collected for this survey.

\begin{tabular}{lccccc}
\hline & \multicolumn{5}{c}{ No. collected leeches } \\
\cline { 2 - 5 } Size class (mm) & $\begin{array}{c}\text { Morning } \\
\text { session }\end{array}$ & $\begin{array}{c}\text { Afternoon } \\
\text { session }\end{array}$ & $\begin{array}{c}\text { Total } \\
\text { No. }\end{array}$ & Age category \\
\hline $6-13$ & 24 & 25 & 49 & 24 & Juvenile \\
$14-21$ & 13 & 14 & 27 & 13 & Juvenile \\
$22-29$ & 18 & 11 & 29 & 14 & Subadult \\
$30-37$ & 41 & 19 & 60 & 30 & Adult \\
$38-45$ & 24 & 12 & 36 & 18 & Adult \\
$46-53$ & 2 & - & 2 & 1 & Adult \\
\hline Total & 122 & 81 & 203 & 100 & \\
\hline
\end{tabular}

also undertaken between 8-10 PM, but the authors subsequently stopped data collection after dusk due to very low leech activity. Collected leeches were preserved individually in vials with 50\% ethanol and labelled with all necessary information (i.e. collection time, locality, the type of habitat and approximate time since the last rainfall).

Animals were measured on the day of collection to reduce the time they were kept in ethanol to only a few hours. Leeches were pinned out to resting length using metal strand to avoid artificial deformation or lengthening of a specimen (Sawyer et al. 1982). Millimetre graph paper was used for morphometrics. Total body length was measured from the margin of an anterior sucker to the margin of a posterior sucker. Body length served as an estimator of relative body size (Ben Ahmed et al. 2009) and six size classes were distinguished for $H$. picta (see Table 1 for details). Individuals with gastric caeca filled with blood were discarded from statistical analyses.

Differences in leech abundance between habitats was assessed using two-way ANOVA. The type of habitat (trail or off-trail) and collecting time after the last rainfall (i.e. up to $5 \mathrm{~h}$, or at least $12 \mathrm{~h}$, after the last rainfall) were entered as fixed independent factors and the number of individuals gathered during a session as the dependent variable. The time after last rainfall, which can be treated as an estimator of humidity (higher shortly after rainfall and lower during longer periods without rain, respectively), was included in the model because it is known to affect the encounter rate of haemadipsid leeches (Kendall 2012). To examine whether 

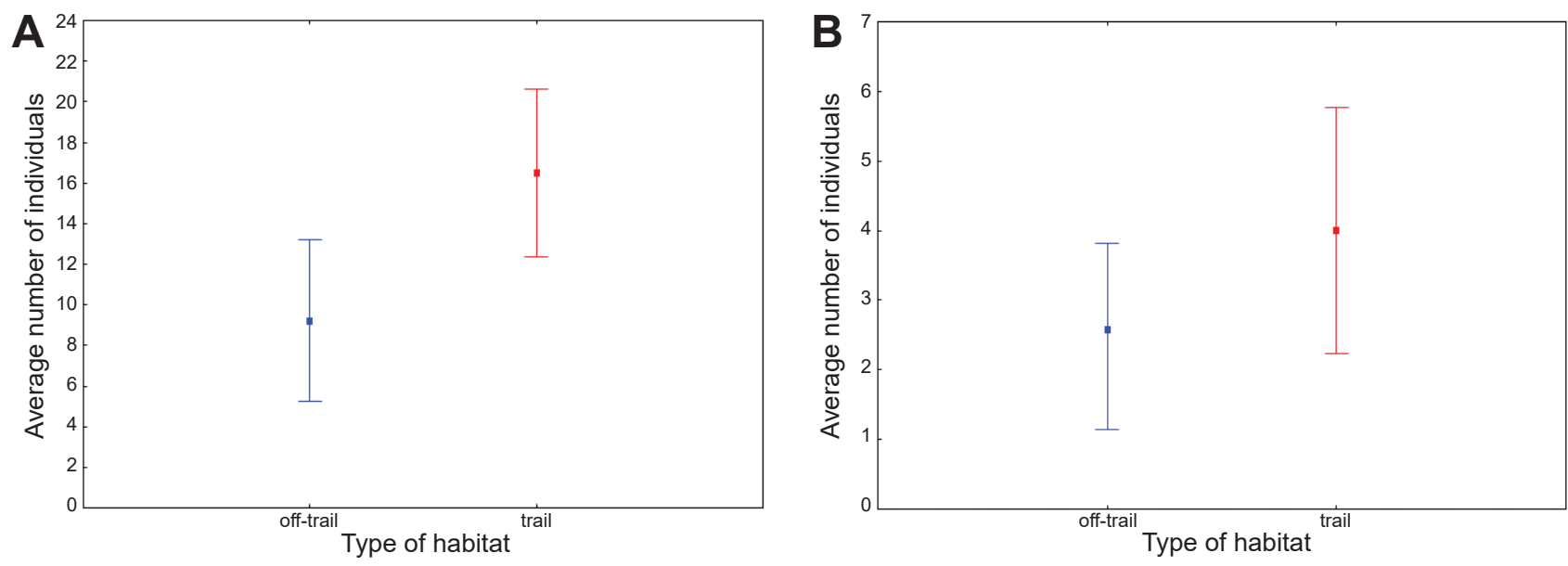

Fig. 2. An average number of individuals (found on $100 \mathrm{~m}^{2}$ plot) occurring in the particular type of habitat. A - Haemadipsa picta Moore, 1929; B - H. subagilis (Moore, 1929). The line segments indicate $95 \%$ confidence intervals.

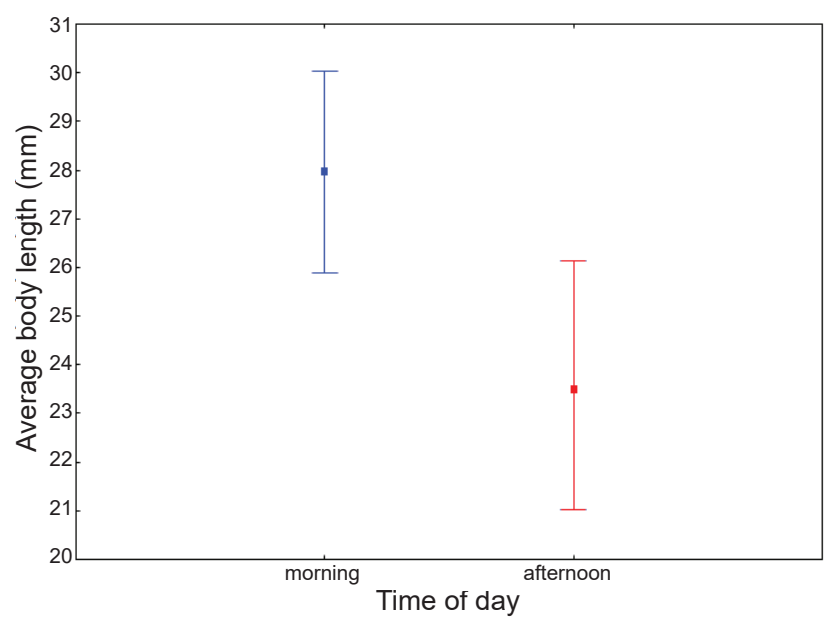

Fig. 3. An average body length (mm) of Haemadipsa picta Moore, 1929 individuals hunting during morning $(\mathrm{M})$ and afternoon (A). The line segments indicate $95 \%$ confidence intervals.

individuals of $H$. picta of distinct body sizes preferred hunting during different times of a day, we applied one-way ANOVA with the time of a day (morning $v s$ late afternoon) as the fixed independent factor and the body length as the dependent variable. We used Kruskal-Wallis test by ranks in the case of $H$. subagilis due to the considerably smaller sample size. To establish if there was significant dependence between size of the specimen and the height from which it attacks a host, non-parametric measure of rank correlation, Spearman's rho, was used. The best fitting curve and equation of non-linear regression were chosen to describe the character of correlation between the tested variables. Standard errors are presented after \pm mark.

\section{RESULTS}

In total 205 individuals of Haemadipsa picta and 54 individuals of $H$. subagilis were collected. More than $90 \%$ of $H$. subagilis were found on the ground, which prevented direct testing of the second hypothesis for this species. Two specimens of $H$. picta and one individual of $H$. subagilis were excluded from the analyses due to evident enlargement of the body after feeding.
Two-way ANOVA revealed statistically significant differences $(\mathrm{F}=7.18, \mathrm{p}=0.02)$ in the abundance of $H$. picta between trails (average number of individuals $/ 100 \mathrm{~m}^{2}$ : $\left.\mathrm{N}_{\mathrm{t}}=16.5 \pm 1.9\right)$ and off-trails $\left(\mathrm{N}_{\mathrm{o}}=9.2 \pm 1.8\right)$, indicating the understory immediately adjacent to trails richer in leeches. No disparities in the abundance of $H$. subagilis were found $\left(\mathrm{F}=2.14, \mathrm{p}=0.17 ; \mathrm{N}_{\mathrm{t}}=2.6 \pm 0.5, \mathrm{~N}_{\mathrm{o}}=4.0 \pm 1.0 ;\right.$ see Fig. 2 for both species), and the impact of rainfall appeared non-significant ( $\mathrm{p}=0.78$ and 0.28 , respectively).

One-way ANOVA confirmed differences in average body length (L) of $H$. picta collected during the morning $(\mathrm{L}=28.0 \pm 1.0)$ and afternoon sessions $(\mathrm{L}=23.6 \pm 1.3$; $\mathrm{F}=6.89, \mathrm{p}=0.01$; see Fig. 3), with larger leeches (i.e. from the third size class onwards, see Table 1) hunting mainly during the morning. Kruskal-Wallis test did not reveal differences in the case of $H$. subagilis $(\mathrm{H}=0.51, \mathrm{p}=0.48)$.

A significant positive correlation between a place of ambush (i.e. the height from which leeches fall onto their hosts or simply attach to them) and body size was discovered for H. picta $(\rho=0.83, \mathrm{p}<0.001)$. The best fit curve, describing these data points had a logarithmic character (see Fig. 4), and the following equation was assigned to this line: $y=30.682 \times \log _{10}(x)-22.7252$. No such correlation was detected for $H$. subagilis $(\rho=-0.08, p=0.56)$.

\section{DISCUSSION}

\section{Inter-habitat dispersion and temporal variation in leech size}

It is widely known that closely related ectoparasites can sometimes inhabit quite different environments (Siddall and Burreson 1996, Williams and Burreson 2006, Borda et al. 2008). Such a pattern is recognised in the Bornean haemadipsid genera: whereas species of Haemadipsa occur in very high numbers in lowland forests (Lai et al. 2011), also occur at higher elevations, i.e. above $800 \mathrm{~m}$ a.s.l. (Moore 1929). In contrast, members of the sister genus Tritetrabdella Moore, 1938 can be found mainly in mountainous areas, i.e. above 1,200 m a.s.1. (Kappes 2013, Nakano et al. 2016). However, the environmental distribution within the members of the same genus remains unclear. 


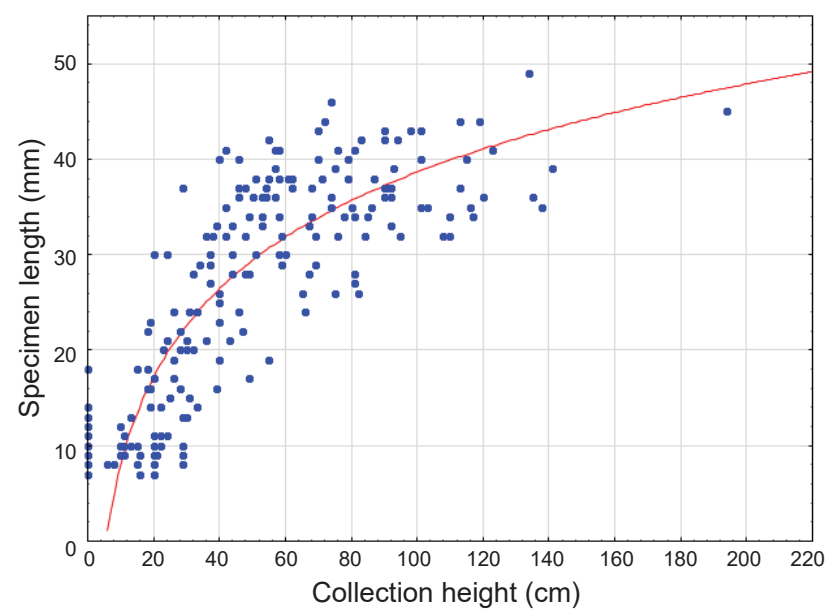

Fig. 4. The dispersion plot depicting the correlation between the length and preferred altitude of attack of Haemadipsa picta Moore, 1929. The best-fitting logarithmic curve is drawn and the following equation of regression is assigned to this curve: $\mathrm{y}=30.682 \times \log 10(\mathrm{x})-22.7252$.

The present study shows that $H$. picta exhibits opportunistic behaviour and agglomerates in the vicinity of animal trails used mainly by mammals such as humans, bearded pigs, macaques and rodents, which logically implies an increase in hunt success ratio. The average number of collected individuals was relatively high in off-trail habitats. It is worth mentioning that host preferences for both species studies are unknown, but Schnell et al. (2015) indicated that mammals and amphibians are hosts of Haemadipsa and Tritetrabdella (see also Rocha et al. 2012 for a brief summary of records of species of Haemadipsa spp. parasitising amphibians).

Lai and Chen (2010) appointed mammals as predominant hosts of leeches of Haemadipsa and our results suggest that these leeches can be choosy in selecting particular hosts of an adequate size. In contrast, we did not find any differences in the abundance of $H$. subagilis across sampled habitats. A considerably lower sample size could have influenced this result, and higher average number of individuals found on trails suggests that significant disparities could be discovered when more leeches are collected and measured.

Demonstrated temporal variation in the size of $H$. picta means that relatively larger specimens (from the third size class onwards, reffered to as 'subadult' herein) prefer hunting during the morning, whereas juveniles (first two size classes) exhibited similar activity throughout the day. Given that leech growth is saltatory, not continuous (Sawyer et al. 1981), this discovery suggests shifts in ecological preferences connected with aging, a factor previously reported as responsible for attenuating interspecific competition between sympatric species (Bashey et al. 2016). Therefore, we hypothesise that a similar mechanism could alleviate intraspecific competition within populations of $H$. picta. In contrast, no such phenomenon was detected for $H$. subagilis. This might suggest that $H$. subagilis exhibits a constant ecological preference throughout its life cycle. However, if the population density is small (e.g. during the dry season
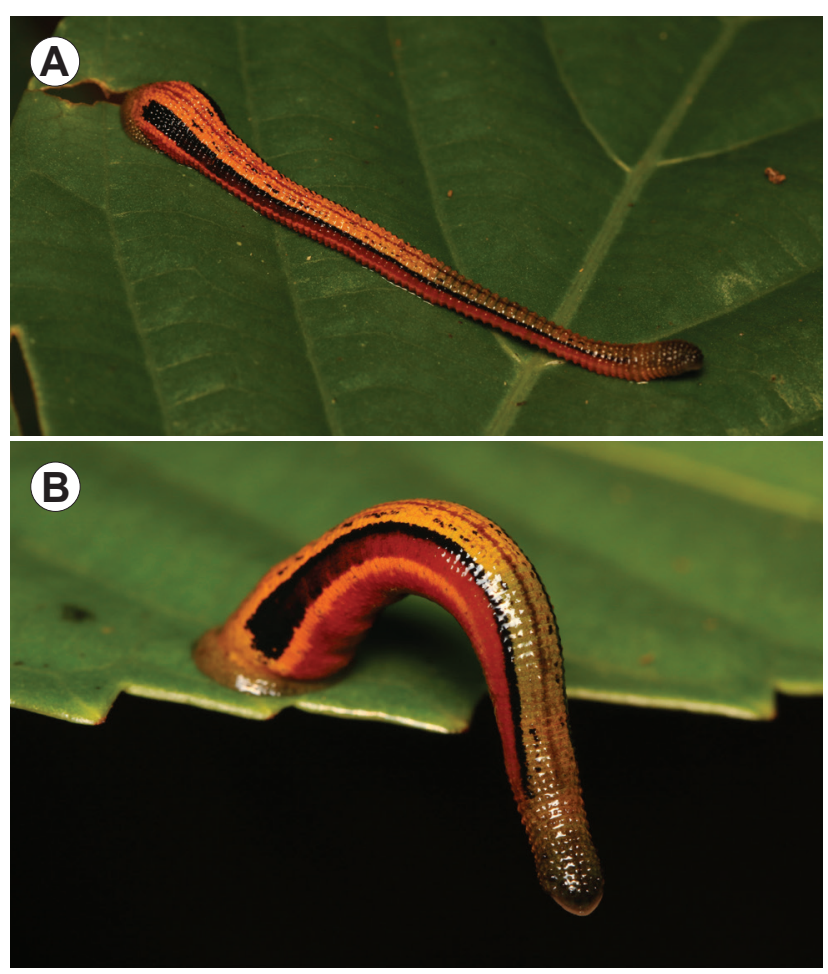

Fig. 5. Typical postures of haemadipsid leeches on the example of Haemadipsa picta Moore, 1929. A - in resting position; B - in attack position. Photo ${ }^{\circ}$ Ryszard Laskowski, used with permission.

in Danum Valley), no aggregations within a particular habitat, or temporal variation would be observed.

\section{Spatial variation in leech size}

Generally, $H$. picta exhibits visible vertical intraspecific niche partitioning. We demonstrated strong correlation between the size of $H$. picta and the height from which it attacks its hosts. The relation has a non-linear character, and is likely shaped by a compromise between (i) energy expenditure associated with foliage climbing, and (ii) the leeches' inclination to select the best place for attack. In other words, it is very profitable for small and intermediate individuals to crawl slightly higher above the surrounding ground level (ranging from $20 \mathrm{~cm}$ to approximately $60 \mathrm{~cm}$ ), as this may increase the host encounter rate and balance the energy expended through movement. Big individuals do not have to climb much higher, because there are no mammalian leech hosts in Bornean rainforest which have a height, as measured at the whiskers, exceeding $2 \mathrm{~m}$ (the biggest, wild cattle - banteng, reaches $1.7 \mathrm{~m}$ ).

As the vast majority of $H$. subagilis were collected from leaf litter, this species must be classified as strictly related to the ground, most probably as other cryptically coloured members of the genus from the brown leech species complex (i.e. former subspecies of $H$. zeylanica Moquin-Tandon, 1827 and cognates; see Borda and Siddall 2010). Nevertheless, six individuals of $H$. subagilis $(11 \%)$ were found on foliage. There are two possible explanations for this: (i) a small fraction of the population inhabits plants up to a height of $1 \mathrm{~m}$; or (ii) the species comprises two or more cryptic taxa, which differ in their preferred microhabitat. 


\section{Intra- and interspecific competition between species of Haemadipsa}

Southeast Asian dipterocarp forests are home to four terrestrial genera whose members very probably do not compete for food resources: many species of Haemadipsa suck blood of mammalians; those of Tritetrabdella that of amphibians (for the latest record see Nakano and Sung 2014); and members of Phytobdella Blanchard, 1894 that of reptiles (Moore 1938). The hosts of species of Planobdella Blanchard, 1894 remain unknown (see Blanchard 1849). The relationships between very closely related species, such as of $H$. picta and $H$. subagilis, were hitherto unravelled. Given that both species occur in lowland forests in very high numbers, one would ask how it is possible they co-exist without outcompeting each other.

Our survey suggests that $H$. picta reduces the level of interspecific competition by adopting a strategy of vertical distribution of individuals, thereby utilising a range of different host species. Further, modulation of intraspecific competition is achieved in two different ways: firstly as a consequence of the vertical distribution discussed above, we hypothesise that juveniles attach to smaller hosts (for example, rodents), and adults to larger hosts (pigs and primates); secondly through temporal separation of hunting periods between specimens of distinct sizes. Recently, Esser et al. (2016) showed that host body size is correlated with tick diversity, namely, the larger the host, the more diverse the ectoparasite fauna. It is therefore possible that host body size also determines the body size in land leeches.

Although we did not show how $H$. subagilis could affect the level of interspecific competition, and the sample size was definitely too low to draw any definite conclusions, over half of collected individuals came from riparian localities. This suggests that $H$. subagilis occupies a more specialised niche in comparison with $H$. picta, presumably due to being more sensitive to low humidity (the best evidence for this is the overall number of $H$. subagilis vs $H$. picta obtained during the dry season). Overall, our results are in agreement with the system described by Johnson and Herbers (2006): two sympatric parasite species inhabit the same environment because of very likely asymmetrical antagonism between them. This results in attenuation of negative effect of ectoparasites on mammals and prevents host population decline. In the case of Haemadipsa leeches, $H$. picta appears to be the stronger competitor, shaping the ecological relationship between species.

\section{Foraging behaviour observations}

The first precise description and classification of leech foraging behaviour was based on observations of the South American species Haementeria ghilianii de Filippi, 1849 (see Sawyer 1981). As H. picta and H. subagilis exhibit differential host search strategies, we report them as follows:

(1) H. picta shows resting posture (Fig. 5A) only when found on foliage. It exhibits both 'head movements' and 'body waving' exploratory behaviours (Fig. 5B), the first typically found in the larger individuals (adult), and the latter behaviour being typical of juveniles. Haemadipsa picta is generally more active and moves more rapidly than its smaller congener, and very often chases potential hosts. Similar behaviour was not observed in $H$. subagilis.

(2) H. subagilis attacks from ambush, i.e. it spends a considerable amount of time in a resting posture, and becomes active and attaches to a host when it comes very close. Immediately before the moment of attachment, an individual almost always performs head movements, but rarely demonstrates body waving.

(3) When H. subagilis attaches to the host's body, it almost never crawls on its host, instead it tries to penetrate the skin near the site of initial attachment.

(4) Differences between modes of movement were also detected during field observations. According to Sawyer (1981), there are two types of leech crawling styles: inchworm and vermiform, differentiated by the position of the body loop during movement, as exhibited by $H$. ghilianii and other leech species of considerable body size. In $H$. picta inchworm crawling of juveniles is replaced by vermiform crawling once an individual matures. Haemadipsa subagilis, although capable of moving in these ways, was observed to prefer vermiform crawling, irrespective of age.

The repertoire of foraging behaviours of other cryptically coloured species of Haemadipsa presumably resembles that of $H$. subagilis. Our observations illustrate the behavioural adaptations of both species to their co-occurence in the uniform environment of the dipterocarp rainforest.

\section{Conclusions and future directions}

Haemadipsa picta aggregates along trails in order to increase its probability of finding a host, whereas such phenomenon was not confirmed for $H$. subagilis. Furthermore, ambush locality is size-dependent in $H$. picta, whereas in H. subagilis, which prefers ambush in the leaf litter, it appears to be a species-specific trait. Finally, H. picta affects the interspecific balance by vertical niche partitioning and very likely influences intraspecific competition by temporal separation of feeding in subadult and adult stages. Further studies are needed to discover habitat preferences of $H$. subagilis. Haemadipsid leeches inhabiting Bornean rainforest evolved different ways of attacking their hosts and, most probably, both species influence the balance between parasite and host populations system, making the coexistence of sympatric species possible. In our opinion, the collection of iDNA (for details see Schnell et al. 2015) from both species and individuals collected from various habitats and plant heights would allow for a more thorough examination of host preferences of leeches and individuals of particular dimensions. They would also deliver very desirable molecular data for a taxonomically challenging group - the brown leech species complex, which has inconsistent spatial dispersion (typically ground-living specimens $v s$ a small fraction of population climbing on plants). Such premise might indicate the coexistence of cryptic species. 
Acknowledgements. Authors are very grateful to two anonymous reviewers for their remarks and linguistic corrections, which greatly improved the paper, and to Brian Blagden for critical reading. Moreover, authors like to thank to their course tutor, Marcin Czarnołęski (Institute of Environmental Sciences, Jagiellonian University), for numerous consultations and advise, to Ryszard Laskowski (Institute of Environmental Sciences, Jagiellonian University) for magnificent images of leeches, and to their friends: Danuta Frydryszak, AlicjaWitwicka and Maciej Barczyk for explorative discussions on various aspects of their research. This study was performed as a part of the Tropical Ecology Field Course of the Jagiellonian University and was supported by the Institute of Environmental Sciences, Faculty of Biology and Earth Sciences (grant no: DS/WBINOZ/INOS/757/2016). The authors declare that they have no competing interests.

\section{REFERENCES}

Anderson R.M., May R.M. 1978: Regulation and stability of host-parasite population interactions: I. Regulatory processes. J. Anim. Ecol. 47: 219-247.

Bashey F., Sarin T., Lively C.M. 2016: Aging alters interspecific competition between two sympatric insect-parasitic nematode species. Ecol. Evol. 6: 3750-3759.

Ben Ahmed R., Ropelewska E., Bielecki A., Cichocka J. 2009: Batracobdella algira Moquin-Tandon, 1846 (Hirudinida: Glossiphoniidae) - morphometric analysis and internal morphology. Wiad. Parazytol. 55: 353-358.

BLANCHARD R. 1849: Recherches sur l'organisation des vers. Ann. Sci. Nat. Zool. 11: 106-202.

Borda E., Oceguera-Figueroa A., Siddall M.E. 2008: On the classification, evolution and biogeography of terrestrial haemadipsoid leeches (Hirudinida: Arhynchobdellida: Hirudiniformes). Mol. Phylogenet. Evol. 46: 142-154.

Borda E., Siddall M.E. 2004: Review of the evolution of life history strategies and phylogeny of the Hirudinida (Annelida: Oligochaeta). Lauterbornia 52: 5-25.

Borda E., Siddall M.E. 2010: Insights into the evolutionary history of Indo-Pacific blood feeding terrestrial leeches (Hirudinida: Arhynchobdellida: Haemadipisdae). Invert. Syst. 24: 456472.

Chin Teh J., Kamarudin M.S., Abd-Rahim A., SaAd C.R., RAMEZANi-FARD E. 2012: Effects of feeding frequency on the survival, growth and body composition of buffalo leech, Hirudinaria manillensis. Asian J. Anim. Vet. Adv. 8: 130-134.

Davies R.W., Kasserra C.E. 1989: Foraging activity of two species of predatory leeches exposed to active and sedentary prey. Oecologia 81: 329-334.

Esser H.J., Foley J.E., Bongers F., Herre E.A., Miller M.J., Prins H.H.T., JANSEN P.A. 2016: Host body size and the diversity of tick assemblages on Neotropical vertebrates. Int. J. Parasitol. Parasites Wildl. 5: 295-304.

Fogden S.C.L., Proctor J. 1985: Notes on the feeding of land leeches (Haemadipsa zeylanica Moore and H. picta Moore) in Gunung Mulu National Park, Sarawak. Biotropica 17: 172-174.

Govedich F.R., Moser W.E., Davies R.W. 2004: Annelida: Clitellata, Hirudinea, Euhirudinea. In: C.M. Yule and H.S. Yong (Eds.), Freshwater Invertebrates of the Malaysian Region, Academy of Sciences Malaysia, Kuala Lumpur, pp. 175-190.

Inger R.F., Greenberg B. 1966: Ecological and competitive relations among three species of frogs (genus Rana). Ecology 47: $746-759$.

Johnson D. 1996: Palms: their conservation and sustained utilization. Status survey and conservation action plan. IUCN/SSC Action Plans for the Conservation of Biological Diversity 8, $116 \mathrm{pp}$.

JoHnSON C.A., Her BERS J.M. 2006: Impact of parasite sympatry on the geographic mosaic of coevolution. Ecology 87: 382-394.

KapPES H. 2013: Genetics and morphology of the genus Tritetrabdella (Hirudinea, Haemadipsidae) from the mountainous rain forests of Sabah, Borneo, reveal a new species with two new subspecies. Contrib. Zool. 82: 185-197.

Kendall A. 2012: The effect of rainforest modification on two species of South-East Asian terrestrial leeches, Haemadipsa zeylanica and Haemadipsa picta. MSc. thesis, Imperial College, London, $29 \mathrm{pp}$.
Kutschera U. 2003: The feeding strategies of the leech Erpobdella octoculata (L.): a laboratory study. Int. Rev. Hydrobiol. 88: 94-101.

Lai Y.-T., Chen, J.-H. 2010: Leech Fauna of Taiwan. Biota Taiwanica. National Taiwan University Press, Taipei, 118 pp.

Lai Y.-T., Nakano T., Chen J.-H. 2011: Three species of land leeches from Taiwan, Haemadipsa rjukjuana comb. n., a new record for Haemadipsa picta Moore, and an updated description of Tritetrabdella taiwana (Oka). ZooKeys 139: 1-22.

Moore J.P. 1929: Leeches from Borneo with description of new species. Proc. Acad. Nat. Sci. Philad. 81: 267-295.

Moore J.P. 1935: Leeches from Borneo and the Malay Peninsula. Bull. Raffles Mus. 10: 67-79.

Moore J.P. 1938: Leeches (Hirudinea) principally from the Malay peninsula, with descriptions of new species. Bull. Raffles Mus. 14: $64-80$.

Nakano T., Jeratthitikul E., Nguyen T.T., Somsak P. 2016: A new species of Tritetrabdella (Hirudinida: Hirudiniformes: Haemadipsidae) from northern Indochina. Raffles Bull. Zool. 64: 105-116.

Nakano T., Sung Y.-H. 2014: A new host record for Tritetrabdella taiwana (Hirudinida: Arhynchobdellida: Haemadipsidae) from the asian painted frog Kaloula pulchra (Anura: Microhylidae) in Hong Kong, China, with a taxonomic note on T. taiwana. Comp. Parasitol. 81: 125-129.

Newbery D.M., Kennedy D.N., Petol G.H., Madani L., RidsDALE C.E. 1999: Primary forest dynamics in lowland dipterocarp forest at Danum Valley, Sabah, Malaysia, and the role of the understorey. Phil. Trans. R. Soc. Lond. B, Biol. Sci. 354: 1763-1782.

Rocha R., Borda E., Andreone F., Rosa G.M. 2012: First reports of leech parasitism in Malagasy anurans. Comp. Parasitol. 79: $352-356$.

SAWYER R.T. 1981: Leech biology and behavior. In: E. Nicholls, K.J. Muller and G.S. Stent (Eds.), Neurobiology of The Leech, Cold Spring Harbor, New York, pp. 7-26.

Sawyer R.T., Lepont F., Stuart D.K., Kramer A.P. 1981: Growth and reproduction of the giant glossiphoniid leech Haementeria ghilianii. Biol. Bull. 160: 322-331.

Sawyer R.T., Taylor A., Sahat M.J.H. 1982: The leeches of Brunei (Annelida: Hirudinea), with a checklist and key to the known and expected freshwater, terrestrial and marine leeches of Borneo. J. Brunei Mus. 5: 168-201.

Schnell I.B., Sollmann R., Calvignac-Spencer S., Siddall M.E., Yu D.W., Wilting A., Gilbert M.T.P. 2015: iDNA from terrestrial haematophagous leeches as a wildlife surveying and monitoring tool - prospects, pitfalls and avenues to be developed. Front. Zool. 12: 24

Siddall M.E., Burreson E.M. 1996: Leeches (Oligochaeta?: Euhirudinea), their phylogeny and the evolution of life-history strategies. Hydrobiologia 334: 277-285.

Sket B., Trontelj P. 2008: Global diversity of leeches (Hirudinea) in freshwater. Hydrobiologia 595: 129-137.

Smythies B.E. 1959: Leeches of Borneo. Sarawak Mus. J. 13: 279-294. 
Williams J.I., Burreson E.M. 2006: Phylogeny of the fish leeches (Oligochaeta, Hirudinida, Piscicolidae) based on nuclear and mitochondrial genes and morphology. Zool. Scr. 35: 627-639.
Willott S.J., Lim D.C., Compton S.G., Sutton S.L. 2000: Effects of selective logging on the butterflies of a Bornean rainforest. Conserv. Biol. 14: 1055-1065.

Cite this article as: Gąsiorek P., Różycka H. 2017: Feeding strategies and competition between terrestrial Haemadipsa leeches (Euhirudinea: Arhynchobdellida) in Danum Valley rainforest (Borneo, Sabah). Folia Parasitol. 64: 031. 